\title{
Article \\ Genotyping and Antimicrobial Susceptibility of Clostridium perfringens and Clostridioides difficile in Camel Minced Meat
}

\author{
Mahmoud Fayez ${ }^{1,2,+} \mathbb{D}$, Waleed R. El-Ghareeb ${ }^{3}$, Ahmed Elmoslemany ${ }^{4}\left(\mathbb{D}\right.$, Saleem J. Alsunaini ${ }^{1}$, \\ Mohamed Alkafafy ${ }^{5}$ (D), Othman M. Alzahrani ${ }^{6}$, Samy F. Mahmoud ${ }^{5}$ and Ibrahim Elsohaby ${ }^{7,8,9, *,+}$
}

check for

updates

Citation: Fayez, M.; El-Ghareeb, W.R.; Elmoslemany, A.; Alsunaini, S.J.; Alkafafy, M.; Alzahrani, O.M.;

Mahmoud, S.F.; Elsohaby, I

Genotyping and Antimicrobial Susceptibility of Clostridium

perfringens and Clostridioides difficile in Camel Minced Meat. Pathogens 2021, 10, 1640. https://doi.org/10.3390/ pathogens 10121640

Academic Editors: Yasser Sanad, Steven Foley and Mohamed K. Fakhr

Received: 13 November 2021 Accepted: 17 December 2021 Published: 19 December 2021

Publisher's Note: MDPI stays neutral with regard to jurisdictional claims in published maps and institutional affiliations.

Copyright: (c) 2021 by the authors. Licensee MDPI, Basel, Switzerland. This article is an open access article distributed under the terms and conditions of the Creative Commons Attribution (CC BY) license (https:// creativecommons.org/licenses/by/ $4.0 /)$.
1 Al-Ahsa Veterinary Diagnostic Lab, Ministry of Environment, Water and Agriculture, Al-Ahsa 31982, Saudi Arabia; mahmoudfayez30@hotmail.com (M.F.); sslam0002@gmail.com (S.J.A.)

2 Department of Bacteriology, Veterinary Serum and Vaccine Research Institute, Ministry of Agriculture, Cairo 11381, Egypt

3 Department of Veterinary Public Health and Animal Husbandry, College of Veterinary Medicine, King Faisal University, P.O. Box 400, Al-Ahsa 31982, Saudi Arabia; welsaid@kfu.edu.sa

4 Hygiene and Preventive Medicine Department, Faculty of Veterinary Medicine, Kafrelsheikh University, Kafr El-Sheikh 33516, Egypt; aelmoslemany@gmail.com

5 Department of Biotechnology, College of Science, Taif University, P.O. Box 11099, Taif 21944, Saudi Arabia; m.kafafy@tu.edu.sa (M.A.); s.farouk@tu.edu.sa (S.F.M.)

6 Department of Biology, College of Science, Taif University, P.O. Box 11099, Taif 21944, Saudi Arabia; o.alzahrani@tu.edu.sa

7 Department of Animal Medicine, Faculty of Veterinary Medicine, Zagazig University, Zagazig 44511, Egypt

8 Department of Health Management, Atlantic Veterinary College, University of Prince Edward Island, Charlottetown, PE C1A 4P3, Canada

9 Department of Infectious Diseases and Public Health, Jockey Club of Veterinary Medicine and Life Sciences, City University of Hong Kong, Kowloon, Hong Kong

* Correspondence: ielsohaby@upei.ca; Tel.: +1-902-566-6063

+ These authors contributed equally to this work.

Abstract: The present study aimed to determine the occurrence, genotypes, and antimicrobial resistance of Clostridium perfringens (C. perfringens) and Clostridioides difficile (C. difficile) in camel minced meat samples collected from small butcher shops and supermarkets in Al-Ahsa Governorate, Saudi Arabia. A total of 100 camel minced meat samples were randomly collected from small butcher's shops $(n=50)$ and supermarkets $(n=50)$ in Al-Ahsa Governorate, Saudi Arabia. C. perfringens and $C$. difficile were isolated and identified using the VITEK-2 compact system and 16S rRNA gene amplification. Genotypes, toxin genes, and antimicrobial susceptibility of the isolates were determined. Moreover, ELISA was used to detect C. perfringens and C. difficile toxins. C. perfringens and C. difficile were isolated from $14 \%$ and $4 \%$ of the tested minced meat samples, respectively. Out of the 14 C. perfringens isolates, type A $(64.3 \%)$, type B $(7.1 \%)$, type $C(21.5 \%)$, and type $\mathrm{D}(7.1 \%)$ were detected. However, out of the four $C$. difficile isolates, three (75\%) were type $\mathrm{A}^{+} \mathrm{B}^{+}$and one (25\%) was type $\mathrm{A}^{-} \mathrm{B}^{+}$. None of the $C$. perfringens or $C$. difficile toxins were identified using ELISA. C. perfringens and $C$. difficile isolates exhibited a high rate of resistance to tetracycline (56\% and $75 \%$, respectively). However, all isolates were susceptible to amoxicillin-clavulanate. Multidrug resistance was observed in three $(21.4 \%)$ C. perfringens and one $(25 \%)$ C. difficile isolates. In conclusion, camel minced meat was contaminated with $C$. perfringens and $C$. difficile, which present a potential risk of food poisoning. The majority of the isolates were resistant to at least one antimicrobial, and some isolates were multidrug-resistant. Therefore, food safety standards and frequent inspections of abattoirs, small butcher shops, and supermarkets should be enforced.

Keywords: C. perfringens; C. difficile; minced meat; camel; toxin genes; genotypes

\section{Introduction}

Food hygiene is described as all the conditions and measures necessary to ensure that food is safe and fit for human consumption during production, processing, storage, distri- 
bution, and preparation [1]. Foodborne diseases are caused by food contamination and can occur at any stage of the food production, delivery, and consumption chain. There are over 200 foodborne hazards, including microbiological hazards such as bacteria, viruses, parasites, and chemical contaminants, that arise naturally or due to pollution, food processing, packaging, transportation, or storage [2]. Foodborne illnesses and outbreaks are among the leading causes of death globally [3,4]. According to studies, the magnitude of foodborne illnesses in 2010 included 600 million illnesses and 420,000 deaths worldwide [5,6]. Nausea, vomiting, retching, diarrhea, abdominal discomfort, prostration, abdominal cramps, fever, chills, headache, and arthralgia are just a few of the symptoms [7].

Clostridia spp. are anaerobic Gram-positive, spore-forming and non-motile bacteria commonly found in the intestinal tract of humans and animals and the soil [8]. Clostridium perfringens (C. perfringens) is the most widespread species and among the most common foodborne pathogens in industrial countries. There are several toxigenic types of $C$. perfringens, including A, B, C, D, and E. However, type A is primarily associated with foodborne illness [9]. C. perfringens food poisoning can occur when cooked meat is not adequately heated or refrigerated before serving. Illness often arises $8-15 \mathrm{~h}$ after consuming contaminated food. The symptoms include strong abdominal cramps, gas, and diarrhea (nausea and infrequent vomiting) [10]. Clostridioides difficile (C. difficile) is also associated with food poisoning, with symptoms ranging from mild diarrhea to life-threatening pseudomembranous colitis [11,12].

The recent rise and re-emergence of antimicrobial-resistant foodborne bacteria necessitate coordinated efforts, particularly in developing countries [13]. Antibacterial resistance can spread through the food chain, either directly or indirectly. Direct exposure happens when a human comes into contact with an animal or its blood, saliva, milk, sperm, feces, or urine. Indirect contact occurs, following consumption of infected food products such as eggs, meat, and dairy products $[14,15]$.

Camel is a versatile animal that is used for milk, meat, wool, transportation, racing, tourism, agricultural work, and beauty contests. Camel meat is a major source of animal protein in many African and Asian countries, particularly in locations where the environment makes it difficult for other animals to produce. Camel meat is healthier than other meat animals since the carcass has less fat and has lower cholesterol levels in the fat. Camel meat also has a higher proportion of polyunsaturated fatty acids than beef $[16,17]$.

In Saudi Arabia, a number of surveys have investigated the prevalence of camel meat contamination with some aerobic bacteria such as Staphylococcus aureus, E. coli, and Salmonella [18-21]. To the best of the authors' knowledge, no literature exists that investigates the anaerobic contamination of camel meat with bacteria. Therefore, the main goal of this study is to determine the occurrence, genotypes and antimicrobial resistance of C. perfringens and C. difficile in camel minced meat samples collected from small butcher shops and supermarkets in Al-Ahsa Governorate, Saudi Arabia.

\section{Results}

\subsection{Isolation and Identification of C. perfringens and C. difficile}

Out of the 100 minced meat samples tested in the present study, $14 \%$ and $4 \%$ were contaminated with C. perfringens and C. difficile, respectively. More than $70 \%$ of the C. perfringens and C. difficile isolates were recovered from samples collected from butcher shops (Table 1).

The number of $C$. perfringens in positive samples ranged from 200 to $2 \times 10^{3} \mathrm{CFU} / \mathrm{g}$. Based on the 16S rRNA sequence analysis, the 14 C. perfringens and four $C$. difficile isolates were clustered with the reference C. perfringens (NR 121697, NR 113204, and NR 112169) and C. difficile (NR 112172), respectively, with a similarity level of $100 \%$ (Figure 1). 
Table 1. The number of $C$. perfringens and C. difficile isolates recovered from camel minced meat samples collected from small butcher shops and supermarkets.

\begin{tabular}{cccc}
\hline \multirow{2}{*}{ Sample Source } & \multirow{2}{*}{ No. of Tested Samples } & \multicolumn{2}{c}{ No. (\%) of } \\
\cline { 3 - 4 } & & C. perfringens & C. difficile \\
\hline Butcher shops & 50 & $10(71.4)$ & $3(75)$ \\
Supermarkets & 50 & $4(28.6)$ & $1(25)$ \\
\hline Total & 100 & $14(14 \%)$ & $4(4 \%)$ \\
\hline
\end{tabular}



Figure 1. Phylogenetic tree based on $16 \mathrm{~S}$ rRNA sequences of $C$. perfringens and C. difficile isolates recovered from camel minced meat samples. The asterisk $\left(^{*}\right)$ refers to $C$. perfringens and C. difficile isolates recovered in this study.

\subsection{Genotyping of C. perfringens and C. difficile Isolates}

PCR genotyping revealed that $C$. perfringens isolated from camel minced meat was related to type $A, B, C$, and $D$, whereas $C$. difficile isolates were related to type $\mathrm{A}^{+} \mathrm{B}^{+}$and $\mathrm{A}^{-} \mathrm{B}^{+}$(Figure 2). 


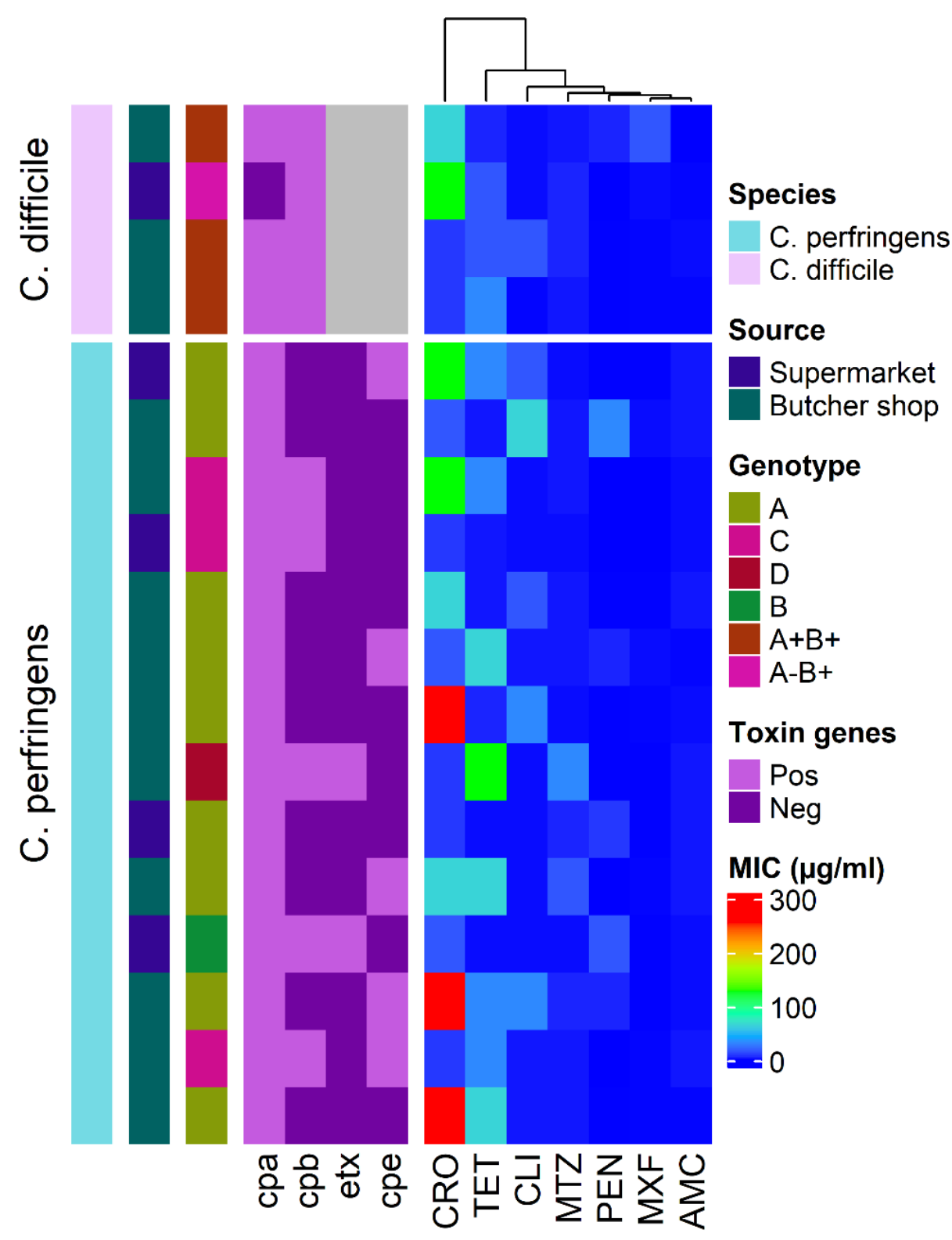

Figure 2. Heat map of the toxin genes and antimicrobial resistance profiles of C. perfringens and C. difficile genotypes recovered from camel minced meat collected from small butcher shops and supermarkets. Antimicrobials are ceftriaxone (CRO), tetracycline (TET), clindamycin (CLI), metronidazole (MTZ), penicillin (PEN), moxifloxacin (MXF), and amoxicillin-clavulanate (AMC).

Table 2 shows the distribution of $C$. perfringens and $C$. difficile types and toxin genes in camel minced meat samples. Out of the 14 C. perfringens isolates, nine (64.3\%) were type A, one $(7.1 \%)$ was type $B$, three $(21.5 \%)$ were type $C$, and one $(7.1 \%)$ was type D. C. perfringens type A with only $c p a^{+}$gene was found in five (55.6\%) isolates and $c p a^{+}$associated $c p e^{+}$ genes were found in four $(44.4 \%)$ isolates. However, out of the four $C$. difficile isolates, three $(75 \%)$ were type $\mathrm{A}^{+} \mathrm{B}^{+}$and one $(25 \%)$ was type $\mathrm{A}^{-} \mathrm{B}^{+}$.

\subsection{Detection of C. perfringens and C. difficile Toxin by ELISA}

None of the $C$. perfringens or $C$. difficile toxins were detected in the supernatant of homogenized meat samples using ELISA. The alpha toxin of C. perfringens was detected by ELISA in culture supernatants from all C. perfringens isolates, but the beta and epsilon toxins were detected in culture supernatants from four and one C. perfringens isolates, respectively. C. difficile alpha and beta toxins were detected in the culture supernatant 
of three isolates, but only beta toxin was detected in one isolate's culture supernatant. Enterotoxin was found in the culture supernatant of four C. perfringens types A and one C. perfringens type $\mathrm{C}$.

Table 2. Distribution of $C$. perfringens and C. difficile types and toxin genes in camel minced meat samples.

\begin{tabular}{|c|c|c|c|c|}
\hline Clostridium spp. & Type & $\mathbf{N}$ & Toxin Gene & No. (\%) \\
\hline \multirow{5}{*}{ C. perfringens } & & & $\mathrm{cpa}^{+}$ & $5(35.7)$ \\
\hline & A & 9 & $c p a^{+}, c p e^{+}$ & $4(28.6)$ \\
\hline & B & 1 & $c p a^{+}, c p b^{+}, e t x^{+}$ & $1(7.1)$ \\
\hline & C & 3 & $c p a^{+}, c p b^{+}$ & $2(14.3)$ \\
\hline & D & 1 & $\begin{array}{c}\text { cpa }, \text { cpo }, \text { epe } \\
\text { cpa }^{+}, \text {etx }\end{array}$ & $\begin{array}{l}1(7.1) \\
1(7.1)\end{array}$ \\
\hline \multirow{2}{*}{ C. difficile } & $\mathrm{A}^{+} \mathrm{B}^{+}$ & 3 & $t c d A, t c d B$ & $3(75)$ \\
\hline & $\mathrm{A}^{-} \mathrm{B}^{+}$ & 1 & $t c d B$ & $1(25)$ \\
\hline
\end{tabular}

\subsection{Antimicrobial Susceptibility}

The distribution of minimum inhibitory concentration (MIC) values of different antimicrobials against the 14 C. perfringens and four $C$. difficile isolates recovered from camel minced meat is shown in Figure 2. C. perfringens and C. difficile isolates had a high frequency of tetracycline (TET) resistance ( $56 \%$ and $75 \%$, respectively), followed by ceftriaxone (CRO) resistance (50\% and 50\%, respectively). All C. perfringens isolates were amoxicillinclavulanate (AMC) and moxifloxacin (MXF) sensitive; however, all C. difficile isolates were only AMC sensitive. The frequency of antimicrobial resistance of $C$. perfringens and $C$. difficile genotypes isolated from camel minced meat is shown in Figure 3. Multidrug resistance was observed in three (21.4\%) C. perfringens and one $(25 \%)$ C. difficile isolates. The mean multiple antibiotic resistance (MAR) index for resistant $C$. perfringens isolates was 0.30 (range 0.14-0.57), and C. difficile isolates was 0.29 (range 0.14-0.43) (Table 3).

Table 3. The antimicrobial-resistant profiles of C. perfringens and C. difficile isolates recovered from camel minced meat samples.

\begin{tabular}{lcccc}
\hline Genotype & Source & Accession No. & Resistance Patterns $^{\mathbf{1}}$ & MAR Index $^{2}$ \\
\hline C. perfringens type C & Supermarket & MW725399 & - & 0.00 \\
C. perfringens type A & Supermarket & MW785765 & PEN & 0.14 \\
C. perfringens type B & Supermarket & MW785767 & PEN & 0.14 \\
C. perfringens type C & Butcher shop & MW785769 & TET & 0.14 \\
C. perfringens type A & Butcher shop & MW725397 & PEN, CLI & 0.29 \\
C. perfringens type C & Butcher shop & MW725398 & CRO, TET & 0.29 \\
C. perfringens type A & Butcher shop & MW725400 & CRO, CLI & 0.29 \\
C. perfringens type A & Butcher shop & MW725401 & PEN, TET & 0.29 \\
C. perfringens type A & Butcher shop & MW785763 & CRO, CLI & 0.29 \\
C. perfringens type D & Butcher shop & MW785764 & MTZ, TET & 0.29 \\
C. perfringens type A & Butcher shop & MW785770 & CRO, TET & 0.29 \\
C. perfringens type A & Supermarket & MW725396 & CRO, CLI, TET & 0.43 \\
C. perfringens type A & Butcher shop & MW785766 & CRO, MTZ, TET & 0.43 \\
C. perfringens type A & Butcher shop & MW785768 & PEN, CRO, CLI, TET & 0.57 \\
C. difficile type A ${ }^{+} B^{+}$ & Butcher shop & MW798269 & TET & 0.14 \\
C. difficile type A ${ }^{+} B^{+}$ & Butcher shop & MW798268 & CLI, TET & 0.29 \\
C. difficile type A ${ }^{-} B^{+}$ & Supermarket & MW732695 & CRO, TET & 0.29 \\
C. difficile type A ${ }^{+} B^{+}$ & Butcher shop & MW732694 & PEN, CRO, MXF & 0.43 \\
\hline
\end{tabular}

${ }^{1}$ CRO: ceftriaxone; CLI: clindamycin; TET: tetracycline; PEN: penicillin; MTZ: metronidazole; MXF: moxifloxacin.

${ }^{2}$ MAR: Multiple antibiotic resistance index. 
(a)

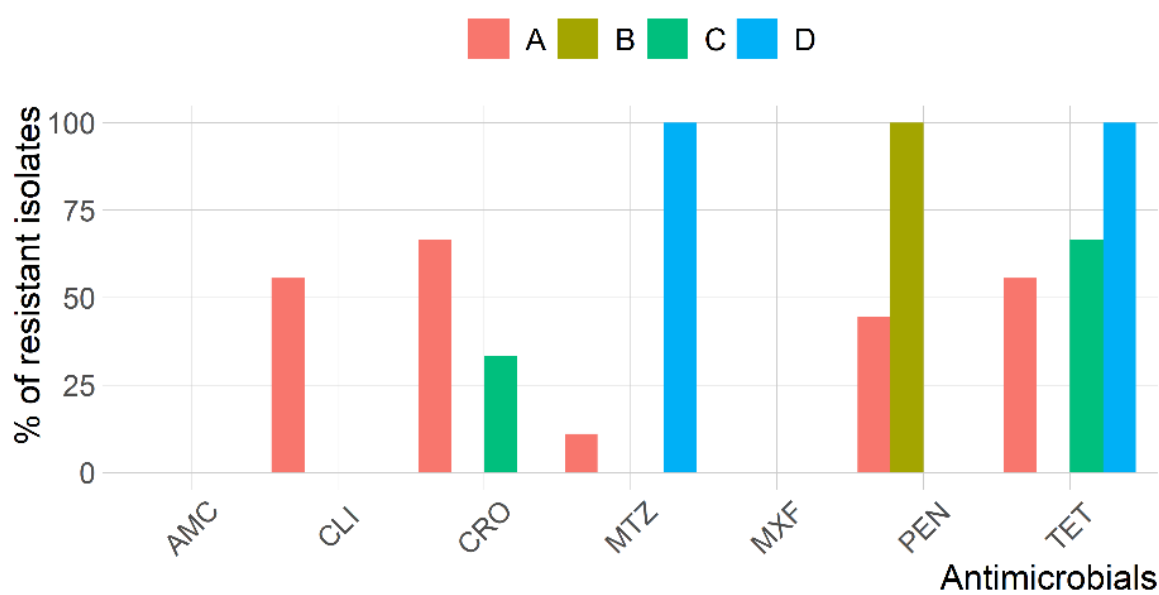

(b)

cpe-

cpe+

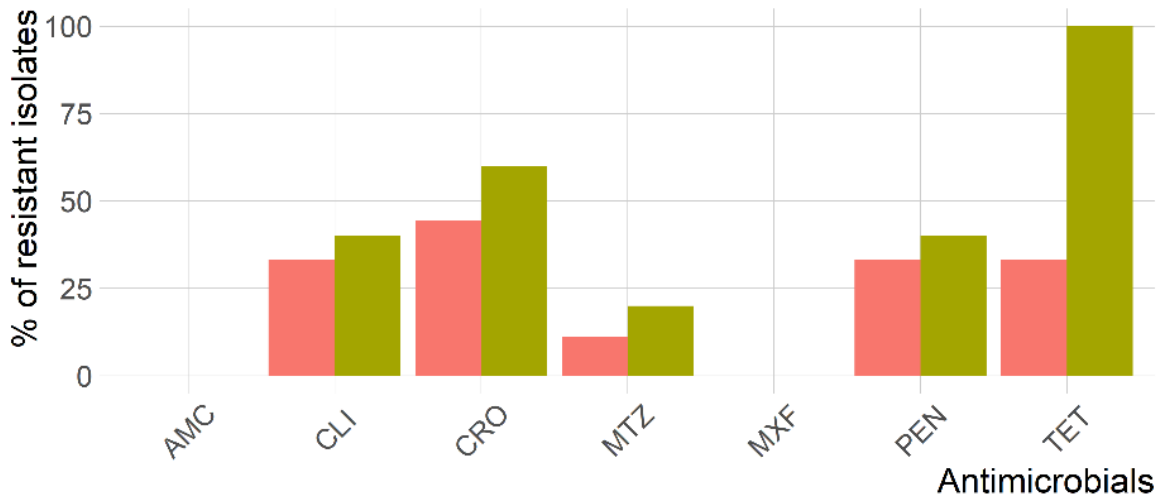

(c)

$\mathrm{A}-\mathrm{B}+\mathrm{A}+\mathrm{B}+$

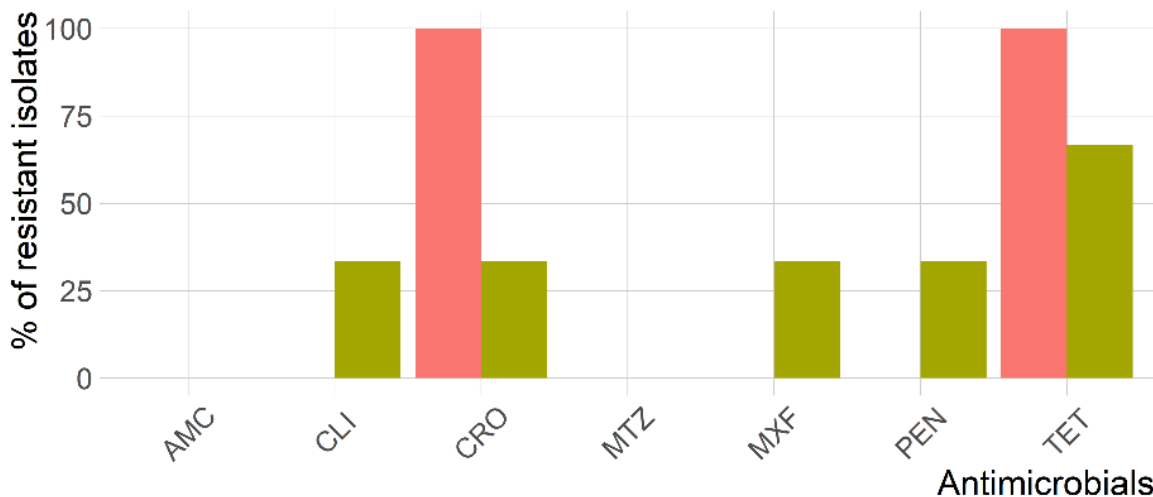

Figure 3. Frequency of antimicrobial resistance of (a) C. perfringens genotypes, (b) C. perfringens enterotoxin gene, and (c) C. difficile genotypes recovered from camel minced meat samples. Antimicrobials are amoxicillin-clavulanate (AMC), clindamycin (CLI), ceftriaxone (CRO), metronidazole (MTZ), moxifloxacin (MXF), penicillin (PEN), and tetracycline (TET). 


\section{Discussion}

Foodborne pathogens cause a wide range of diseases, with serious consequences for human health and the economy. C. perfringens is one of the most common foodborne pathogens that contaminate many types of retail meat products and cause food poisoning in humans and domestic animals [22]. Several studies have investigated the occurrence and genotypes of $C$. perfringens in retail food, including chicken [23], beef [24], and sheep [25] meats. However, few studies have determined C. perfringens genotypes and antimicrobial resistance in camel meat $[26,27]$.

In the present study, C. perfringens was isolated from $14 \%$ of the tested minced meat samples. This finding is consistent with previous studies that reported the occurrence of C. perfringens in $33.7 \%$ [27] and 2.7\% [26] of tested camel meat samples and swabs, respectively. On the other hand, previous studies have reported the occurrence of C. perfringens in $18 \%$ of tested minced meat in Turkey [28]; $21.2 \%$ of beef slaughtering and butchering processes in China [29]; 44.3\% of goat, sheep, and cattle meat in Pakistan [30]; and 23.5\% of raw processed meat in South Africa [31].

Clostridium perfringens types A, B, C, and D have been isolated in this study and type A $(64.3 \%)$ was the most prevalent, followed by type C (21.5\%). Several studies that investigated the distribution of $C$. perfringens types in retail food samples have reported that C. perfringens type A was the most common among the types recovered from camel [26,27], beef [24] and sheep [25] meats. However, a recent study in Korea detected only C. perfringens type A (33\%) in tested chicken and beef meat samples [32]. In another study conducted in sheep meat, C. perfringens type A was not detected, and types B, C, and D were isolated [33]. All types of C. perfringens are commensal in the gastrointestinal tract of animals, therefore, contamination during slaughter and butchering could be the primary source of $C$. perfringens in meats $[34,35]$.

Toxin genes (cpa, $c p b, c p e$, and $e t x)$ were found on the $C$. perfringens isolates recovered in our study. Although all C. perfringens isolates were found to be associated with cpa ${ }^{+}$ gene, only five $(35.7 \%)$ isolates were associated with the enterotoxins $\left(c p e^{+}\right)$gene, which is responsible for nearly all C. perfringens food poisoning outbreaks $[25,36,37]$. Similarly, previous studies found that all $C$. perfringens isolates from meat samples were positive for $\mathrm{cap}^{+}$gene [38,39], suggesting that it might be a universal gene in C. perfringens isolated from meat samples [40]. Moreover, the $c p e^{+}$gene has been detected in $1.4 \%$ [25], 5\% [41], and $27.2 \%$ [42] of $C$. perfringens isolated from raw and processed meats. In contrast, a recent study did not find $\mathrm{cpe}^{+}$gene in any of the C. perfringens isolates recovered from meat samples in Korea [32].

Clostridium difficile infections have been increased globally in the last two decades, causing severe intestinal infections in humans $[43,44]$. Thus, the occurrence of $C$. difficile has been detected in $4 \%$ of camel minced meat used in this study, and all isolates were identified as toxigenic. This finding is consistent with previous studies that isolated $C$. difficile from $1.9 \%$ of ground beef samples in France [45], 5\% of ground beef and hamburger samples in Sweden [46], and 6.3\% of lamb meat samples in the Netherlands [47]. However, C. difficile was not detected in ground beef in Switzerland [48] and Austria [49]. Food animals are known carriers of $C$. difficile [50], and multiple reports show $C$. difficile shedding in animals at slaughter [51,52]. Contamination of meats may occur due to gut content leakage during evisceration or due to the accumulation of spores within the slaughterhouse environment [53]. The discovery of genetically identical C. difficile strains in food, livestock, and humans has raised awareness for $C$. difficile potential as an unspecific foodborne agent $[54,55]$.

ELISA can detect $C$. perfringens and C. difficile toxins. In the current investigation, neither $C$. perfringens nor $C$. difficile toxins were found in camel minced meat. In comparison, C. perfringens toxins were found in $13 \%$ of minced meat samples in Turkey [28]. Although C. perfringens and C. difficile were isolated from some samples, they were toxin negative, which could be related to the fact that some clostridia are incapable of making toxins [25] or the toxin concentration in the samples may be below the ELISA detection limit $(5 \mathrm{ng} / \mathrm{mL})$. 
In Saudi Arabia, antimicrobials have been used in livestock to promote growth and prevent several infectious diseases. However, their use has paradoxically increased the bacterial resistance to antimicrobials [56,57]. In this study, C. perfringens and C. difficile isolates exhibited a high resistance rate to TET (56\% and 75\%, respectively). However, all isolates were susceptible to AMC. Similarly, previous reports have shown that C. perfringens and $C$. difficile isolates are highly resistant to TET $[39,57,58]$ and are susceptible to betalactams [58,59]. In South Korea, more than 93\% of C. perfringens isolates from beef, poultry, duck, and pork meats were tetracycline resistant [60]. Furthermore, many investigations have found that beta-lactam antibiotics, such as ampicillin, can inhibit C. perfringens isolated from beef, poultry, and pork meats from the United States, Belgium, Scandinavia, and India $[61,62]$.

Multidrug resistance has been reported in C. perfringens [62,63] and C. difficile $[64,65]$ isolates from retail meats. In the present study, $21.4 \%$ of $C$. perfringens and $25 \%$ of $C$. difficile isolates from camel minced meat showed multidrug resistance, higher than the prevalence of multidrug-resistant observed in other studies [11,32,61]. Overuse of antimicrobials (over-the-counter antibiotics without a prescription), use of TET as a growth promoter, and extensive international travel to Saudi Arabia [66] are all possible explanations for the high resistance rate found in this study. In addition, the prevalence and/or emergence of multidrug-resistant $C$. perfringens has been increasing and poses a tremendous public health concern [67]. A recent study has reported that multidrug resistance bacteria in retail meats originates primarily in veterinary healthcare settings or on farms where animals are administered antibiotics in their feeds or treat diseases [68].

The limitation of this study is the small number of minced meat samples collected. However, the collected samples represent only one district and do not represent different regions of Saudi Arabia. Despite this limitation, the study identified that camel meat was contaminated with $C$. perfringens and $C$. difficile and further studies are warranted to determine their prevalence and zoonotic potential.

\section{Materials and Methods}

\subsection{Sample Collection}

A total of 100 camel minced meat samples were randomly collected from small butcher's shops $(n=50)$ and supermarkets $(n=50)$ in Al-Ahsa Governorate, Saudi Arabia, from September 2019 to June 2020. Approximately $100 \mathrm{gm}$ of minced meat was collected aseptically in sterile plastic bags and stored at $4{ }^{\circ} \mathrm{C}$ until processing within $12-24 \mathrm{~h}$. For sample processing, $25 \mathrm{gm}$ of each sample was aseptically placed in a sterile plastic bag containing $225 \mathrm{~mL}$ sterile peptone solution (Oxoid, Basingstoke, Hampshire, UK) and homogenized using a stomacher at low speed for $3 \mathrm{~min}$.

\subsection{Isolation and Counting of C. perfringens}

A plate count of viable $C$. perfringens was performed according to Rhodehamel and Harmon [10]. Briefly, homogenized meat samples were serially diluted $\left(10^{-1}\right.$ to $\left.10^{-6}\right)$ using a sterile peptone diluent. Dilutions were thoroughly mixed by gentle shaking before each transfer. An aliquot of $0.1 \mathrm{~mL}$ of each dilution was inoculated into Tryptose-sulfitecycloserine (TSC) agar (HiMedia, Mumbai, India) containing egg yolk emulsion (Oxoid, Basingstoke, Hampshire, UK), then spread over agar surface with sterile glass rod spreader. All plates were incubated at $37^{\circ} \mathrm{C}$ under anaerobic conditions for $24 \mathrm{~h}$. Plates showing 20-200 black colonies surrounded by white zone were selected for counting.

For isolation, five suspected colonies from each plate were selected and inoculated into a freshly prepared thioglycollate broth, then incubated under anaerobic conditions at $37^{\circ} \mathrm{C}$ for $24 \mathrm{~h}$. For each sample, a loopful was then sub-cultured into 5\% sheep blood agar and incubated anaerobically for purification. Colonies were identified based on Gram staining and hemolysis on blood agar. Colonies showing Gram-positive rods and hemolysis on agar were selected for further automated biochemical identification by VITEK-2 compact system using VITEK-2 ANC card for Anaerobes (BioMerieux, Marcyl'Etoile, France). A 
reference strain of C. perfringens ATCC 19574 was used as a control. Purified isolates were sub-cultured into fluid thioglycollate broth and incubated for $24 \mathrm{~h}$ under anaerobic conditions to further detect $C$. perfringens toxins in the culture supernatant.

\subsection{Isolation of $C$. difficile}

The broth enrichment method was used to isolate C. difficile [69]. Briefly, 25 gm of minced meat was thoroughly homogenized with $25 \mathrm{~mL}$ phosphate-buffered saline ( $\mathrm{pH} 7.4)$ in a sterile container. One $\mathrm{mL}$ of the homogenate was inoculated into $9 \mathrm{~mL}$ C. difficile moxalactam and norfloxacin broth (CDMN) (Oxoid, Basingstoke, Hampshire, UK), then incubated under anaerobic conditions at $37^{\circ} \mathrm{C}$ for $48 \mathrm{~h}$. An aliquot of the broth was subjected to alcohol shock by adding an equal volume of anhydrous ethanol for $1 \mathrm{~h}$ in a sterile tube. The tubes were then centrifuged at $1900 \mathrm{~g}$ for $10 \mathrm{~min}$. Pellets were inoculated into CDMN agar and incubated anaerobically at $37^{\circ} \mathrm{C}$ for $48 \mathrm{~h}$. Five suspicious colonies were sub-cultured onto $5 \%$ sheep blood agar for purification. Isolates were identified based on Gram staining, colony morphology, and production of proline aminopeptidase. Further biochemical identification was performed by VITEK-2 compact system using VITEK-2 ANC card for Anaerobes (BioMerieux, Marcyl'Etoile, France). A reference strain of $C$. difficile ATCC 43596 was used as a control. Recovered isolates were sub-cultured in TY medium ( $3 \% \mathrm{w} / \mathrm{v}$ tryptose, $2 \% \mathrm{w} / \mathrm{v}$ yeast extract, and $0.1 \% \mathrm{w} / \mathrm{v}$ thioglycollate) for $48 \mathrm{~h}$ at $37^{\circ} \mathrm{C}$ for detection of $\mathrm{C}$. difficile toxins.

\subsection{Molecular Identification and Genotyping}

Genomic DND was extracted and purified from all C. perfringens and C. difficile isolates using QIAamp DNA mini kit (Qiagen, Courtaboeuf, France) according to the manufacturer's instructions.

\subsubsection{S rRNA Gene Amplification and Sequencing}

The extracted DNA $(2 \mu \mathrm{L})$ was amplified in $20 \mu \mathrm{L}$ of the final volume of 2 X HotStartTaq ${ }^{\circledR}$ Plus Master Mix Kit (QIAGEN, Germantown, MD, USA) and $0.5 \mathrm{~mm}$ of each forward (LPW58, 5' - AGGCCCGGGAACGTATTCAC-' 3 ) and reverse (LPW81, 5' -TGGCG AACGGGTGAGTAA'3) primers. Thermo-cycling conditions were performed in Bio-Rad iCycler Thermal Cycler (Bio-Rad Laboratories, Hercules, CA, USA) as described by Woo, et al. [70]. PCR products were purified by the QIA quick PCR purification kit (Qiagen, Courtaboeuf, France). Purified products were sequenced using an ABI 3500 Genetic analyzer (Applied Biosystems, Foster City, CA, USA). The 16S rRNA gene sequences were subjected to analysis via the National Center for Biological Information (NCBI) Basic Local Alignment Search Tool (https:/ /blast. ncbi.nlm.nih.gov / Blast.cgi; accessed on 11 March 2021) and have been deposited in the GeneBank with accession numbers (MW725396-MW725401, MW732694, MW732695 and MW785763-MW798269).

\subsubsection{Detection of C. perfringens and C. difficile Toxin Genes by Real-Time PCR}

C. perfringens toxin genes including alpha (cpa), beta (cpb), epsilon (etx), and enterotoxin (сpe) toxin genes, were amplified by real-time PCR using specific primers and probes previously designed by Gurjar, et al. [71]. The $20 \mu \mathrm{L}$ uniplex reaction mix containing $8 \mu \mathrm{L}$ PCR grade water, $4 \mu \mathrm{L}$ of 5X FastStart DNA Master Plus (Roche Diagnostics, Mannheim, Germany), $1 \mu \mathrm{L}$ of forward and reverse primers, $1 \mu \mathrm{L}$ of Taqman hybridization probe, and $5 \mu \mathrm{L}$ DNA template. Cycling conditions comprised initial denaturation at $95^{\circ} \mathrm{C}$ for $10 \mathrm{~min}$ followed by 40 cycles of denaturation $\left(95^{\circ} \mathrm{C}\right.$ for $30 \mathrm{~s}$ ) and annealing and extension $\left(55^{\circ} \mathrm{C}\right.$ for $1 \mathrm{~min}$ ) using Light cycler 2.0 (Roche Applied Science, Penzberg, Germany). Negative results were considered when no amplification was recorded or when $\mathrm{Ct}$ value was higher than 36 cycle.

C. difficile toxins $\mathrm{A}(t c d A)$ and $\mathrm{B}(t c d B)$ were amplified using a commercial kit (RealStar Clostridium difficile PCR Kit, Altona Diagnostics, Hamburg, Germany) according to the manufacturer's instructions in Light cycler 2.0. 


\subsection{Detection of C. perfringens and C. difficile Toxin by ELISA}

Minced meat samples were homogenized and centrifuged at 17,096 $g$ for $10 \mathrm{~min}$, and the supernatant was filtrated through a sterile $0.45 \mu \mathrm{m}$ syringe filter in a sterile tube. Sandwich ELISA kits (Multiscreen AgELISA Enterotoxemia, Bio-X Diagnostics, Jemelle, Belgium) were used to detect $C$. perfringens toxins (alpha, beta and epsilon) according to the manufacturer's instructions. However, for detection of enterotoxin, the overnight growth of $C$. perfringens in cooked meat media was heat-inactivated at $75^{\circ} \mathrm{C}$ for $20 \mathrm{~min}$ then subcultured in modified Duncan and Strong Medium [72] and incubated at $37^{\circ} \mathrm{C}$ for $24 \mathrm{~h}$. Cells were removed by centrifugation, and the enterotoxin was detected in the supernatant by a commercial latex test (PET-RPLA Toxin Detection Kit, Oxoid, Basingstoke, Hampshire, UK) as per the manufacturer's instructions. Commercial ELISA Kits (Ridascreen Clostridium difficile Toxin A/B, R Biopharm AG, Germany) were used to detect $C$. difficile toxin A/B following the manufacturer's guidelines.

\subsection{Antimicrobial Susceptibility Testing}

The MIC was determined by broth microdilution methods. Seven different antimicrobials (penicillin (PEN, $\geq 2 \mu \mathrm{g} / \mathrm{mL}$ ), amoxicillin-clavulanate (AMC, $\geq 16 \mu \mathrm{g} / \mathrm{mL}$ ), ceftriaxone (CRO, $\geq 64 \mu \mathrm{g} / \mathrm{mL}$ ), moxifloxacin (MXF, $\geq 8 \mu \mathrm{g} / \mathrm{mL}$ ), clindamycin (CLI, $\geq 8 \mu \mathrm{g} / \mathrm{mL}$ ), metronidazole (MTZ, $\geq 32 \mu \mathrm{g} / \mathrm{mL}$ ), and tetracycline (TET, $\geq 16 \mu \mathrm{g} / \mathrm{mL}$ )) from seven different antimicrobial classes were used to assess the antimicrobial susceptibility of both C. perfringens and C. difficile. Antimicrobial solutions were prepared, and a double-fold dilution in brucella broth $(0.125-256 \mu \mathrm{g} / \mathrm{mL})$ was performed in a sterile microtiter plate. A fresh culture from overnight growth was adjusted to $0.5 \mathrm{McFarland}$ standard $\left(10^{6} \mathrm{CFU} / \mathrm{mL}\right)$ and added to each dilution before being incubated at $37^{\circ} \mathrm{C}$ for $48 \mathrm{~h}$ under anaerobic conditions. The MIC values were determined according to the Clinical Laboratory Standards Institute $[73,74]$. Sterile brucella broth and C. perfringens ATCC 19574 cultures were included in each run as negative and positive controls to assess the method reliability. The MAR index was calculated (number of antimicrobials that isolate showed resistance/total number of antimicrobials that isolate had been evaluated for susceptibility) [75]. However, multidrug resistance was defined as resistance to at least three antimicrobial classes [76].

\subsection{Data Analysis}

Collected data were visualized with R software (R Core Team, 2019; version 3.5.3), and the "Complex-Heatmap" R package was used to build heatmap [77]. Phylogenetic analysis was performed using MEGA (version 11) software. Multiple sequence alignments were then performed by ClustalW, and the neighbour-joining method with 1000 bootstrap was used to establish the phylogenetic tree.

\section{Conclusions}

Results of this work show that camel minced meat was contaminated with C. perfringens and C. difficile. Moreover, our results provide further evidence on the emergence of multidrug-resistant strains. Thus, food safety standards and frequent inspections of abattoirs, small butcher shops, and supermarkets should be enforced. Furthermore, proactive antimicrobial agent control measures should be developed to limit the spread of multidrug-resistant strains.

Author Contributions: Conceptualization, M.F., A.E. and I.E.; methodology, M.F., W.R.E.-G., S.J.A., M.A., O.M.A. and S.F.M.; software, M.F., A.E. and I.E.; validation, M.F., W.R.E.-G., S.J.A., M.A., O.M.A. and S.F.M.; formal analysis, M.F., A.E. and I.E.; investigation, M.F., W.R.E.-G., S.J.A., M.A., O.M.A. and S.F.M.; resources, M.F., S.J.A., M.A., O.M.A. and S.F.M.; data curation, M.F., W.R.E.-G., M.A., O.M.A. and S.F.M.; writing-original draft preparation, M.F. and I.E.; writing-review and editing, W.R.E.-G., A.E., S.J.A., M.A., O.M.A. and S.F.M.; visualization, I.E.; supervision, M.F. and S.J.A.; project administration, M.F. and S.J.A.; funding acquisition, O.M.A. All authors have read and agreed to the published version of the manuscript. 
Funding: Taif University Researchers Supporting Project number (TURSP-2020/262), Taif University, P.O. Box 11099, Taif 21944, Saudi Arabia.

Institutional Review Board Statement: The Taif University Ethics Committee has approved the study protocol (TURSP-2020-262).

Informed Consent Statement: Not applicable.

Data Availability Statement: The data presented in this study are available on request from the corresponding author.

Acknowledgments: The authors would like to thank the Al-Ahsa Veterinary Diagnostic Laboratory staff, Saudi Arabia, for technical assistance and sample collection. The authors would also like to thank the Taif University Researchers Supporting Program (Project number: TURSP-2020/262), Taif University, Saudi Arabia for their support.

Conflicts of Interest: The authors declare no conflict of interest.

\section{References}

1. World Health Organization. The Role of food Safety in Health and Development: Report of a Joint FAO/WHO Expert Committee on Food Safety; World Health Organization: Geneva, Switzerland, 1984; p. 79.

2. Mead, P.S.; Slutsker, L.; Dietz, V.; McCaig, L.F.; Bresee, J.S.; Shapiro, C.; Griffin, P.M.; Tauxe, R.V. Food-related illness and death in the United States. Emerg. Infect. Dis. 1999, 5, 607. [CrossRef]

3. Flint-Garcia, S.A.; Thuillet, A.C.; Yu, J.; Pressoir, G.; Romero, S.M.; Mitchell, S.E.; Doebley, J.; Kresovich, S.; Goodman, M.M.; Buckler, E.S. Maize association population: A high-resolution platform for quantitative trait locus dissection. Plant J. 2005, 44, 1054-1064. [CrossRef]

4. McIntyre, L.; Vallaster, L.; Wilcott, L.; Henderson, S.B.; Kosatsky, T. Evaluation of food safety knowledge, attitudes and selfreported hand washing practices in FOODSAFE trained and untrained food handlers in British Columbia, Canada. Food Control 2013, 30, 150-156. [CrossRef]

5. Havelaar, A.H.; Kirk, M.D.; Torgerson, P.R.; Gibb, H.J.; Hald, T.; Lake, R.J.; Praet, N.; Bellinger, D.C.; De Silva, N.R.; Gargouri, N. World Health Organization global estimates and regional comparisons of the burden of foodborne disease in 2010. PLoS Med. 2015, 12, e1001923. [CrossRef] [PubMed]

6. Hoffmann, S.; Devleesschauwer, B.; Aspinall, W.; Cooke, R.; Corrigan, T.; Havelaar, A.; Angulo, F.; Gibb, H.; Kirk, M.; Lake, R. Attribution of global foodborne disease to specific foods: Findings from a World Health Organization structured expert elicitation. PLoS ONE 2017, 12, e0183641. [CrossRef]

7. CDC. CDC, What Is a Foodborne Disease Outbreak and Why Do They Occur. 2012. Available online: http://www.cdc.gov/ foodsafety / facts.html\#whatisanoutbreak. (accessed on 20 August 2021).

8. McClane, B.A.; Uzal, F.A.; Miyakawa, M.F.; Lyerly, D.; Wilkins, T. The enterotoxic clostridia. Prokaryotes 2006, 4, 698-752.

9. Miyamoto, K.; Nagahama, M. Clostridium: Food poisoning by Clostridium perfringens. In Encyclopedia of Food and Health; Caballero, B., Finglas, P.M., Toldrá, F., Eds.; Academic Press: Oxford, UK, 2016; pp. 149-154.

10. Rhodehamel, E.; Harmon, S. BAM: Clostridium perfringens; US FDA: Rockville, MD, USA, 2001.

11. Rodriguez-Palacios, A.; Staempfli, H.R.; Duffield, T.; Weese, J.S. Clostridium difficile in retail ground meat, Canada. Emerg. Infect. Dis. 2007, 13, 485. [CrossRef]

12. Songer, J.G.; Trinh, H.T.; Killgore, G.E.; Thompson, A.D.; McDonald, L.C.; Limbago, B.M. Clostridium difficile in retail meat products, USA, 2007. Emerg. Infect. Dis. 2009, 15, 819. [CrossRef] [PubMed]

13. Odeyemi, O.; Sani, N. Antibiotic resistance and burden of foodborne diseases in developing countries. Future Sci. OA 2016, 2, FSO139. [CrossRef]

14. Chang, Q.; Wang, W.; Regev-Yochay, G.; Lipsitch, M.; Hanage, W.P. Antibiotics in agriculture and the risk to human health: How worried should we be? Evol. Appl. 2015, 8, 240-247. [CrossRef]

15. Liu, Y.-Y.; Wang, Y.; Walsh, T.R.; Yi, L.-X.; Zhang, R.; Spencer, J.; Doi, Y.; Tian, G.; Dong, B.; Huang, X. Emergence of plasmidmediated colistin resistance mechanism MCR-1 in animals and human beings in China: A microbiological and molecular biological study. Lancet Infect. Dis. 2016, 16, 161-168. [CrossRef]

16. Dawood, A.A.; Alkanhal, M.A. Nutrient composition of Najdi-camel meat. Meat Sci. 1995, 39, 71-78. [CrossRef]

17. Al-Ani, F. Camel Management and Disease, 1st ed.; Al. Sharq Printing Press: Ar-Rayyan, Qatar; Dar-Ammar Book Publisher: Amman, Jordan, 2004.

18. Bosilevac, J.M.; Gassem, M.A.; Al Sheddy, I.A.; Almaiman, S.A.; Al-Mohizea, I.S.; Alowaimer, A.; Koohmaraie, M. Prevalence of Escherichia coli O157: H7 and Salmonella in camels, cattle, goats, and sheep harvested for meat in Riyadh. J. Food Prot. 2015, 78, 89-96. [CrossRef]

19. Raji, M.A.; Garaween, G.; Ehricht, R.; Monecke, S.; Shibl, A.M.; Senok, A. Genetic characterization of Staphylococcus aureus isolated from retail meat in Riyadh, Saudi Arabia. Front. Microbiol. 2016, 7, 911. [CrossRef] [PubMed] 
20. El-Ghareeb, W.R.; Almathen, F.S.; Fayez, M.M.; Alsultan, R.A. Methicillin resistant Staphylococcus aureus (MRSA) in camel meat: Prevalence and antibiotic susceptibility. Slov. Vet. Res. 2019, 56, 249-256. [CrossRef]

21. El-Ghareeb, W.R.; Abdel-Raheem, S.M.; Al-Marri, T.M.; Alaql, F.A.; Fayez, M.M. Isolation and identification of extended spectrum $\beta$-lactamases (ESBLs) Escherichia coli from minced camel meat in Eastern province, Saudi Arabia. Thai J. Vet. Med. 2020, 50, 155-161.

22. McClane, B.A.; Robertson, S.L.; Li, J. Clostridium perfringens. In Food Microbiology: Fundamentals and Frontiers; Wiley \& Sons: New York, NY, USA, 2012; pp. 465-489.

23. Nowell, V.J.; Poppe, C.; Parreira, V.R.; Jiang, Y.-F.; Reid-Smith, R.; Prescott, J.F. Clostridium perfringens in retail chicken. Anaerobe 2010, 16, 314-315. [CrossRef]

24. Miki, Y.; Miyamoto, K.; Kaneko-Hirano, I.; Fujiuchi, K.; Akimoto, S. Prevalence and characterization of enterotoxin gene-carrying Clostridium perfringens isolates from retail meat products in Japan. Appl. Environ. Microbiol. 2008, 74, 5366-5372. [CrossRef] [PubMed]

25. Wen, Q.; McClane, B.A. Detection of enterotoxigenic Clostridium perfringens type A isolates in American retail foods. Appl. Environ. Microbiol. 2004, 70, 2685-2691. [CrossRef]

26. Basma, S.; AM, E.M. Detection of enterotoxigenic Clostridium perfringens type: A in camel meat. Vet. Med. J. 2006, 54, 179-188.

27. Mohamed, M.E.; I Suelam, I.; Saleh, M.A. The presence of toxin genes of Clostridium perfringens isolated from camels and humans in Egypt. Vet. Arh. 2010, 80, 383-392.

28. Kamber, U.; Gokce, H.; Elmali, M. Clostridium perfringens and its toxins in minced meat from Kars, Turkey. Food Addit. Contam. 2007, 24, 673-678. [CrossRef] [PubMed]

29. Jiang, Y.; Ma, Y.; Liu, Q.; Li, T.; Li, Y.; Guo, K.; Zhang, Y. Tracing Clostridium perfringens strains from beef processing of slaughter house by pulsed-field gel electrophoresis, and the distribution and toxinotype of isolates in Shaanxi province, China. Food Microbiol. 2022, 101, 103887. [CrossRef] [PubMed]

30. Khan, M.A.; Khan, S.B.; Khan, I.U.; Sultan, A.; Khan, R.; Shahid, M.; Aqib, A.I.; Khan, S.; Khan, A.Z.; Hassan, M. The prevalence of Clostridium perfringens in retail meat of Mardan, Pakistan. Turk. J. Vet. Anim. Sci. 2020, 44, 618-623. [CrossRef]

31. Madoroba, E.; Magwedere, K.; Chaora, N.S.; Matle, I.; Muchadeyi, F.; Mathole, M.A.; Pierneef, R. Microbial Communities of Meat and Meat Products: An Exploratory Analysis of the Product Quality and Safety at Selected Enterprises in South Africa. Microorganisms 2021, 9, 507. [CrossRef]

32. Jang, Y.-S.; Kim, D.-H.; Bae, D.; Kim, S.-H.; Kim, H.; Moon, J.-S.; Song, K.-Y.; Chon, J.-W.; Seo, K.-H. Prevalence, toxin-typing, and antimicrobial susceptibility of Clostridium perfringens from retail meats in Seoul, Korea. Anaerobe 2020, 64, 102235. [CrossRef]

33. Guran, H.S.; Vural, A.; Erkan, M.E. The prevalence and molecular typing of Clostridium perfringens in ground beef and sheep meats. J. Verbraucherschutz Lebensmittelsicherheit 2014, 9, 121-128. [CrossRef]

34. Uzal, F.A.; Songer, J.G. Diagnosis of Clostridium perfringens intestinal infections in sheep and goats. J. Vet. Diagn. Investig. 2008, 20, 253-265. [CrossRef]

35. Fayez, M.; Elsohaby, I.; Al-Marri, T.; Zidan, K.; Aldoweriej, A.; El-Sergany, E.; Elmoslemany, A. Genotyping and antimicrobial susceptibility of Clostridium perfringens isolated from dromedary camels, pastures and herders. Comp. Immunol. Microbiol. Infect. Dis. 2020, 70, 101460. [CrossRef]

36. Collie, R.E.; McClane, B.A. Evidence that the enterotoxin gene can be episomal in Clostridium perfringens isolates associated with non-food-borne human gastrointestinal diseases. J. Clin. Microbiol. 1998, 36, 30-36. [CrossRef]

37. Sparks, S.G.; Carman, R.J.; Sarker, M.R.; McClane, B.A. Genotyping of enterotoxigenic Clostridium perfringens fecal isolates associated with antibiotic-associated diarrhea and food poisoning in North America. J. Clin. Microbiol. 2001, 39, 883-888. [CrossRef]

38. Brynestad, S.; Granum, P.E. Clostridium perfringens and foodborne infections. Int. J. Food Microbiol. 2002, 74, 195-202. [CrossRef]

39. Llanco, L.; Nakano, V.; Ferreira, A.; Avila-Campos, M. Toxinotyping and antimicrobial susceptibility of Clostridium perfringens isolated from broiler chickens with necrotic enteritis. Int. J. Food Microbiol. Res. 2012, 4, 290.

40. Petit, L.; Gibert, M.; Popoff, M.R. Clostridium perfringens: Toxinotype and genotype. Trends Microbiol. 1999, 7, 104-110. [CrossRef]

41. Freedman, J.C.; Shrestha, A.; McClane, B.A. Clostridium perfringens enterotoxin: Action, genetics, and translational applications. Toxins 2016, 8, 73. [CrossRef]

42. Yibar, A.; Cetin, E.; Ata, Z.; Erkose, E.; Tayar, M. Clostridium perfringens contamination in retail meat and meat-based products in Bursa, Turkey. Foodborne Pathog. Dis. 2018, 15, 239-245. [CrossRef]

43. Lessa, F.C.; Mu, Y.; Bamberg, W.M.; Beldavs, Z.G.; Dumyati, G.K.; Dunn, J.R.; Farley, M.M.; Holzbauer, S.M.; Meek, J.I.; Phipps, E.C. Burden of Clostridium difficile infection in the United States. N. Engl. J. Med. 2015, 372, 825-834. [CrossRef]

44. Kola, A.; Wiuff, C.; Akerlund, T.; van Benthem, B.H.; Coignard, B.; Lyytikäinen, O.; Weitzel-Kage, D.; Suetens, C.; Wilcox, M.H.; Kuijper, E.J. Survey of Clostridium difficile infection surveillance systems in Europe, 2011. Eurosurveillance 2016, $21,30291$. [CrossRef]

45. Bouttier, S.; Barc, M.-C.; Felix, B.; Lambert, S.; Collignon, A.; Barbut, F. Clostridium difficile in ground meat, France. Emerg. Infect. Dis. 2010, 16, 733. [CrossRef]

46. Von Abercron, S.M.M.; Karlsson, F.; Wigh, G.T.; Wierup, M.; Krovacek, K. Low occurrence of Clostridium difficile in retail ground meat in Sweden. J. Food Protect. 2009, 72, 1732-1734. [CrossRef] 
47. De Boer, E.; Zwartkruis-Nahuis, A.; Heuvelink, A.E.; Harmanus, C.; Kuijper, E.J. Prevalence of Clostridium difficile in retailed meat in the Netherlands. Int. J. Food Microbiol. 2011, 144, 561-564. [CrossRef] [PubMed]

48. Hofer, E.; Haechler, H.; Frei, R.; Stephan, R. Low occurrence of Clostridium difficile in fecal samples of healthy calves and pigs at slaughter and in minced meat in Switzerland. J. Food Protect. 2010, 73, 973-975. [CrossRef] [PubMed]

49. Jöbstl, M.; Heuberger, S.; Indra, A.; Nepf, R.; Köfer, J.; Wagner, M. Clostridium difficile in raw products of animal origin. Int. J. Food Microbiol. 2010, 138, 172-175. [CrossRef]

50. Dubberke, E.R.; Haslam, D.B.; Lanzas, C.; Bobo, L.D.; Burnham, C.A.; Gröhn, Y.T.; Tarr, P.I. The ecology and pathobiology of Clostridium difficile infections: An interdisciplinary challenge. Zoonoses Public health 2011, 58, 4-20. [CrossRef]

51. Rodriguez-Palacios, A.; Pickworth, C.; Loerch, S.; LeJeune, J.T. Transient fecal shedding and limited animal-to-animal transmission of Clostridium difficile by naturally infected finishing feedlot cattle. Appl. Environ. Microbiol. 2011, 77, 3391-3397. [CrossRef] [PubMed]

52. Weese, J.S.; Rousseau, J.; Deckert, A.; Gow, S.; Reid-Smith, R.J. Clostridium difficile and methicillin-resistant Staphylococcus aureus shedding by slaughter-age pigs. BMC Vet. Res. 2011, 7, 1-7. [CrossRef] [PubMed]

53. EFSA, E. European Food Safety Authority and European Centre for Disease Prevention and Control. EFSA J. $2015,13,4329$.

54. Janezic, S.; Zidaric, V.; Pardon, B.; Indra, A.; Kokotovic, B.; Blanco, J.L.; Seyboldt, C.; Diaz, C.R.; Poxton, I.R.; Perreten, V. International Clostridium difficile animal strain collection and large diversity of animal associated strains. BMC Microbiol. 2014, 14, 1-10. [CrossRef]

55. Knight, D.R.; Elliott, B.; Chang, B.J.; Perkins, T.T.; Riley, T.V. Diversity and evolution in the genome of Clostridium difficile. Clin. Microbiol. Rev. 2015, 28, 721-741. [CrossRef] [PubMed]

56. Immerseel, F.V.; Buck, J.D.; Pasmans, F.; Huyghebaert, G.; Haesebrouck, F.; Ducatelle, R. Clostridium perfringens in poultry: An emerging threat for animal and public health. Avian Pathol. 2004, 33, 537-549. [CrossRef] [PubMed]

57. Hosseinzadeh, S.; Bahadori, M.; Poormontaseri, M.; Dehghani, M.; Fazeli, M.; Nazifi, S. Molecular characterization of Clostridium perfringens isolated from cattle and sheep carcasses and its antibiotic resistance patterns in Shiraz slaughterhouse, southern Iran. Vet. Arh. 2018, 88, 581-591. [CrossRef]

58. Beran, V.; Chmelar, D.; Vobejdova, J.; Konigova, A.; Nemec, J.; Tvrdik, J. Sensitivity to antibiotics of Clostridium difficile toxigenic nosocomial strains. Folia Microbiol. 2014, 59, 209-215. [CrossRef]

59. Hmood, A.M.; Al-Shukri, M.S.; Al-Charrakh, A.H. Molecular detection and antimicrobial resistance of Clostridium perfringens isolated from diabetic patients and bullet wounds. J. Appl. Biol. Biotechnol. 2019, 7, 54-59.

60. Hu, W.-S.; Kim, H.; Koo, O.K. Molecular genotyping, biofilm formation and antibiotic resistance of enterotoxigenic Clostridium perfringens isolated from meat supplied to school cafeterias in South Korea. Anaerobe 2018, 52, 115-121. [CrossRef]

61. Gharaibeh, S.; Al Rifai, R.; Al-Majali, A. Molecular typing and antimicrobial susceptibility of Clostridium perfringens from broiler chickens. Anaerobe 2010, 16, 586-589. [CrossRef] [PubMed]

62. Yadav, J.P.; Das, S.C.; Dhaka, P.; Vijay, D.; Kumar, M.; Mukhopadhyay, A.K.; Chowdhury, G.; Chauhan, P.; Singh, R.; Dhama, K. Molecular characterization and antimicrobial resistance profile of Clostridium perfringens type A isolates from humans, animals, fish and their environment. Anaerobe 2017, 47, 120-124. [CrossRef]

63. Kiu, R.; Hall, L.J. An update on the human and animal enteric pathogen Clostridium perfringens. Emerg. Microbes Infect. 2018, 7, 1-15. [CrossRef]

64. Mooyottu, S.; Flock, G.; Kollanoor-Johny, A.; Upadhyaya, I.; Jayarao, B.; Venkitanarayanan, K. Characterization of a multidrug resistant C. difficile meat isolate. Int. J. Food Microbiol. 2015, 192, 111-116. [CrossRef] [PubMed]

65. Zhang, W.-Z.; Li, W.-G.; Liu, Y.-Q.; Gu, W.-P.; Zhang, Q.; Li, H.; Liu, Z.-J.; Zhang, X.; Wu, Y.; Lu, J.-X. The molecular characters and antibiotic resistance of Clostridioides difficile from economic animals in China. BMC Microbiol. 2020, 20, 1-7. [CrossRef] [PubMed]

66. Zowawi, H.M. Antimicrobial resistance in Saudi Arabia: An urgent call for an immediate action. Saudi Med. J. 2016, 37, 935. [CrossRef]

67. Ngamwongsatit, B.; Tanomsridachchai, W.; Suthienkul, O.; Urairong, S.; Navasakuljinda, W.; Janvilisri, T. Multidrug resistance in Clostridium perfringens isolated from diarrheal neonatal piglets in Thailand. Anaerobe 2016, 38, 88-93. [CrossRef]

68. Doyle, M.E. Multidrug-resistant pathogens in the food supply. Foodborne Pathog. Dis. 2015, 12, 261-279. [CrossRef] [PubMed]

69. Weese, J.S.; Avery, B.P.; Rousseau, J.; Reid-Smith, R.J. Detection and enumeration of Clostridium difficile spores in retail beef and pork. Appl. Environ. Microbiol. 2009, 75, 5009-5011. [CrossRef]

70. Woo, P.; Lau, S.; Chan, K.; Fung, A.; Tang, B.; Yuen, K. Clostridium bacteraemia characterised by 16S ribosomal RNA gene sequencing. J. Clin. Pathol. 2005, 58, 301-307. [CrossRef]

71. Gurjar, A.; Hegde, N.; Love, B.; Jayarao, B. Real-time multiplex PCR assay for rapid detection and toxintyping of Clostridium perfringens toxin producing strains in feces of dairy cattle. Mol. Cell. Probes 2008, 22, 90-95. [CrossRef]

72. Duncan, C.L.; Strong, D.H. Improved medium for sporulation of Clostridium perfringens. Appl. Microbiol. 1968, 16, 82-89. [CrossRef] [PubMed]

73. CLSI. Clinical and Laboratory Standards Institute. Methods for Antimicrobial Susceptibility Testing of Anaerobic Bacteria, 9th ed.; CLSI standard M11; Clinical and Laboratory Standards Institute: Wayne, PA, USA, 2018.

74. CLSI. Clinical and Laboratory Standards Institute. Performance Standards for Antimicrobial Susceptibility Testing, 30th ed.; CLSI Supplement M100; Clinical and Laboratory Standards Institute: Wayne, PA, USA, 2020. 
75. Singh, S.; Yadav, A.S.; Singh, S.M.; Bharti, P. Prevalence of Salmonella in chicken eggs collected from poultry farms and marketing channels and their antimicrobial resistance. Food Res. Int. 2010, 43, 2027-2030. [CrossRef]

76. Magiorakos, A.-P.; Srinivasan, A.; Carey, R.; Carmeli, Y.; Falagas, M.; Giske, C.; Harbarth, S.; Hindler, J.; Kahlmeter, G.; OlssonLiljequist, B. Multidrug-resistant, extensively drug-resistant and pandrug-resistant bacteria: An international expert proposal for interim standard definitions for acquired resistance. Clin. Microbiol. Infect. 2012, 18, 268-281. [CrossRef]

77. Gu, Z.; Eils, R.; Schlesner, M. Complex heatmaps reveal patterns and correlations in multidimensional genomic data. Bioinformatics 2016, 32, 2847-2849. [CrossRef] [PubMed] 